\title{
Influence of Buffer Size Change in Critical Chain Scheduling: Case Study
}

\author{
N. Abidah and M.H. Al Hazza
}

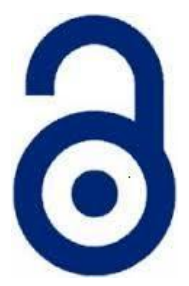

\author{
Received: 17 Martch 2021 \\ Accepted: 04 April 2021 \\ Published: 15 April 2021 \\ Publisher: Deer Hill Publications \\ (c) 2021 The Author(s) \\ Creative Commons: CC BY 4.0
}

\begin{abstract}
Performing the Critical Chain Scheduling (CCS) and Buffer Management (BM) in project management has recently risen as one of the most popular project management approaches. The critical Chain Scheduling (CCS) approach is replacing the traditional scheduling method to reduce the uncertainty associated with time schedules. The research highlights the importance of critical chain scheduling in project execution by investigating using buffers in the critical paths and the feeding baths in project management using a real case study. The case study was studied by analyzing the schedule provided and then implementing CCS and BM using four different methods. The methods are cut and paste (C\&PM), the root square method (RSEM), the Adaptive procedure with resource tightness, and the Adaptive procedure with network density (APND). The buffer size obtained for each method was determined. From the result got, for project buffer in adaptive approach with network density method yields a larger buffer size compared to the adaptive procedure with resource tightness method. While for feeding buffer also show that APND resulted in a larger buffer size than APRT. Finally, the proposed buffer size was investigated and simulated using the What if approach.
\end{abstract}

Keywords: Project management, Critical chain, Buffer, Buffer sizing.

\section{INTRODUCTION}

The project manager's leading role is to achieve the project objectives on time within the budget. One of the challenges of this role is the critical activities with zero or low time tolerances. The project activities in the critical chain are the activities that have zero lead time. These dependent activities and activities close to the critical chain with low lead time need to be managed effectively and beneficially because any delay in those activities will delay the project completion time. From 1956 until 1997, project managers used two main scheduling tools: The critical Path Method (CPM) and the project management review technique (PERT). CPM was developed from 1956 to 1958 by DuPont de Nemours and Company in conjunction with the Univac Applications Research Center of Remington Rand [1]. In 1957, PERT was developed by the U.S. Navy Special Projects Office on the Polaris missile system to support the nuclear submarine projects [2]. CPM is based on focusing on the float or the time each activity can delay without affecting the project's total completion time. However, PERT is considering the probability of finishing the project on time scheduled. Finally, PERT and CPM integrated to take both methods' advantages to be valuable tools and techniques in project scheduling named CPM/PERT. In 1997, a new improvement was introduced by Goldratt 1997 [3], known as critical chain project management (CCPM). The fundamental principle of CCPM is by using the critical chain instead of the critical path [4]. Leach [5] said that CCPM is improving by aggregating the uncertainties at the end of paths that protect the overall project completion on the critical chain path and protect the feeding buffers by protecting the critical chain from path merging. However, the critical chain technique for overcoming uncertainty in a project offers that buffers are added at the end of the critical chain and feed chains [6].

Zhao et al. [4] proposed improving a two-stage approach focusing on the feeding buffer. They suggest solving the conflict that may happen. The precedence conflict or source conflict can be solved by rescheduling that will lead to a noncritical chain that may start earlier than a critical chain in critical chain activities. Bhattacharjee [7] lists the benefit of applying critical chain scheduling (CCS) instead of the Critical Path Method (CPM) or PERT. Firstly, avoid

\author{
N. Abidah', M. Hazza² $₫$ \\ 'Department of Manufacturing and Materials Engineering \\ International Islamic University Malaysia \\ PO Box 10, 50728 Kuala Lumpur, Malaysia \\ ${ }^{2}$ Mechanical and Industrial Engineering Department \\ School of Engineering, American University of Ras Al Khaimah \\ United Arab Emirates \\ E-mail: muataz.alhazza@aurak.ac.ae
}

Reference: N. Abidah and M. Hazza (2021). Influence of Buffer Size Change in Critical Chain Scheduling: Case Study. International Journal of Engineering Materials and Manufacture, 6(2), 95-101. 
uncertainties that may occur within the project duration. The due dateline for each activity is not fixed and emphasizes the project's completion date. Secondly, more assured activity duration estimation- two measures, which are realistic 90\% confidence and aggressive estimation $50 \%$ confidence. Aggressive activity estimation is used in CCS to avoid excessive activity's working time. Thirdly, if the schedule completion date of $50 \%$ estimation is not met, it will protect the project. Reduce the bottleneck's impact in the schedule-feeding buffer to protect the critical chain from variation in the noncritical chain.

In another paper, Chuan \& Gershwing [8] share the buffering concept in manufacturing to ensure the production line runs smoothly by maintaining enough supplies even if there are variations or fluctuations in the production process or demand chain, production capacities, and lead time. Buffer often supplies the raw material and inventories of the finished products waiting for the shipment. For instance, if there is a delay in suppliers' lead time, the raw material buffer can compensate the shortage for the following production process. Thus, this can contribute to the minimization of loss and can maximize the efficiency of the process. According to Büchmann [9], the buffers can be material buffers, resource buffers, equipment buffers, or some entity to protect the production flow. However, this is limited to study about time buffer in the project schedule. In his paper, Büchmann stated there two types of time buffer for scheduling:

a) Activity buffers: applied to each activity in the schedule to protect the variability in production, such as incidents and fluctuation in demand.

b) Stage buffer - to protect unexpected occasions that might happen between activities.

Thus, to prevent delays happen, the buffers are allocated to a specific position with different functions. Categories of the buffers are divided into three types that according to their positions. Project buffer is the time buffer added to the end of the chain to protect project delivery time. Feeding buffers is the time buffer allocated at every noncritical path and feed the critical chain to prevent the slack on a critical task. Lastly, Resource buffers are the alert used to indicate that the resource is needed to perform an activity. Project buffer plays the most crucial role in production scheduling. As it is located at the end of critical path, the project buffer size affects most the whole project's duration, so the project buffer must be determined reasonably. As a result, determining the buffer size is a crucial for project success. Tukel et al., [10] addressed five different simulation methods for determining feeding buffer sizes in CCS: cut and paste method, root square error method, adaptive procedure with resource tightness, adaptive procedure with density, and adaptive procedure with resource tightness.

\section{CASE STUDY}

The case study is named 'Schedule the Chocolate production for XYZ brand. The project network diagram is presented in figure 1, representing the project activities according to their precedence, duration, and resources. The activity durations are shown in days while the respective resources are presented in the alphabet. The renewable resource required to perform the activity is identified as $A, B, C, D, E$, and $F$ at the respective nodes. The availability of each resource is different is $A, B, C, D E, F$, and $G$ availability is one

In applying a critical chain, each task's duration must be estimated almost to half of the expected duration. The schedule duration shortened after the activity duration is estimated aggressively. From 196 days of project duration, the time was reduced to 99 days only. The critical chain also can be identified as the longest chain. In Figure 2, the red box indicates the chain of critical activities.

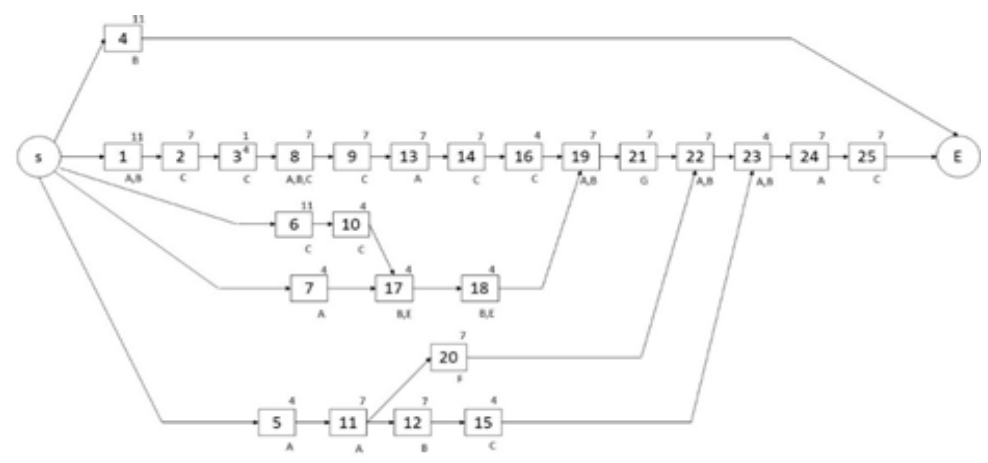

Figure 1: Project network 
Project critical chain consists of the sequences of task 1-2-3-8-9-11-14-16-19-21-22-23-24-25, and the essential length of the chain is equal to 99 days. Project buffer is placed at the end of the critical chain. While feeding buffer is placed at the end of the noncritical chain that feeds to the critical chain. Figure 3 shows the buffer in a blue box. There are 3 feeding buffers, and 1 project buffer are placed. Using the data in Table 1, the calculation is being done using two method of calculation.

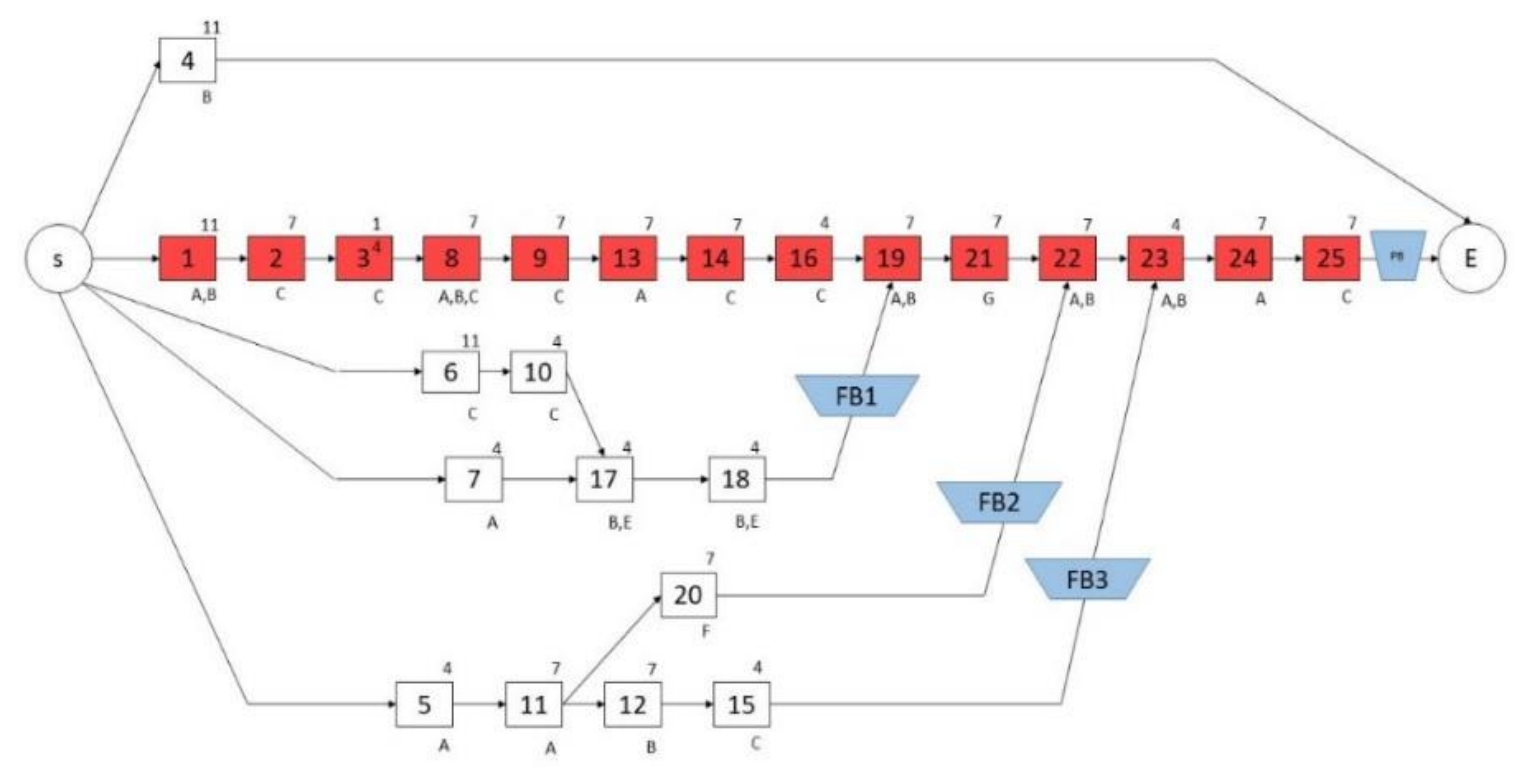

Figure 2: Critical chain

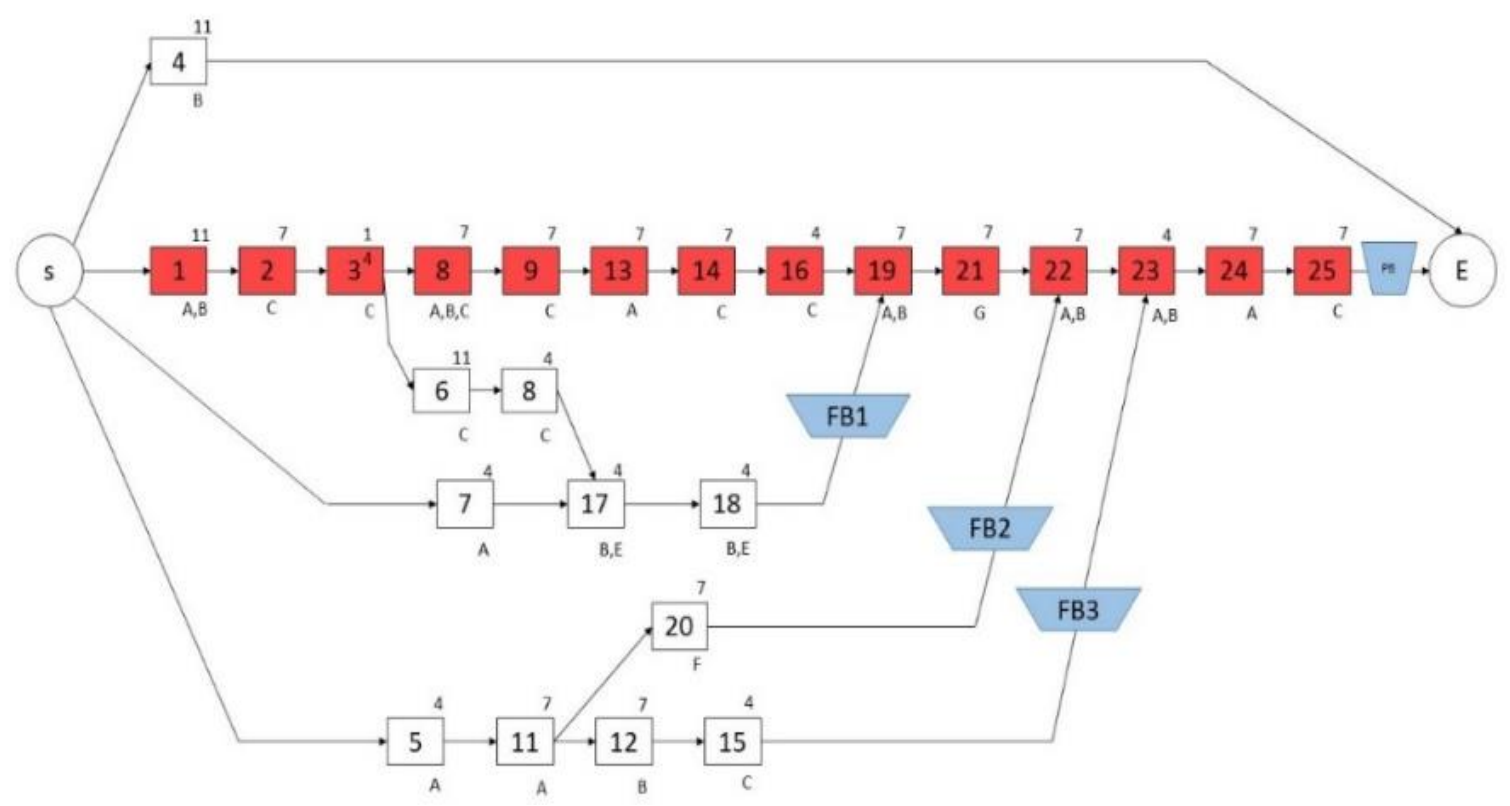

Figure 3: Buffer location 
Table 1: Project data

\begin{tabular}{|c|c|c|c|c|}
\hline Activity & Normal duration & Aggressive duration & Differences & $50 \%$ of differences \\
\hline 1 & 14 & 7 & 7 & 3.5 \\
\hline 2 & 14 & 7 & 7 & 3.5 \\
\hline 3 & 28 & 14 & 14 & 5 \\
\hline 4 & 21 & 11 & 3 & 1.5 \\
\hline 5 & 7 & 4 & 10 & 5 \\
\hline 6 & 21 & 11 & 3 & 1.5 \\
\hline 7 & 7 & 4 & 7 & 3.5 \\
\hline 8 & 14 & 7 & 7 & 3.5 \\
\hline 9 & 14 & 7 & 3 & 3.5 \\
\hline 10 & 7 & 4 & 7 & 3.5 \\
\hline 11 & 14 & 7 & 7 & 3.5 \\
\hline 13 & 14 & 7 & 7 & 3.5 \\
\hline 14 & 14 & 7 & 7 & 1.5 \\
\hline 15 & 14 & 4 & 3 & 1.5 \\
\hline 16 & 7 & 4 & 3 & 1.5 \\
\hline 17 & 7 & 4 & 3 & 1.5 \\
\hline 18 & 7 & 4 & 3 & 3.5 \\
\hline 20 & 7 & 7 & 7 & 3.5 \\
\hline 21 & 14 & 7 & 7 & 3.5 \\
\hline 23 & 14 & 7 & 7 & 3.5 \\
\hline 25 & 14 & 7 & 7 & 1.5 \\
\hline & 14 & 4 & 3 & 3.5 \\
\hline & 7 & 7 & 7 & 3.5 \\
\hline
\end{tabular}

\section{RESULTS AND DISCUSSIONS}

The calculation for each buffer size method is started by calculating the standard deviation. The standard deviation for each activity is computed by $50 \%$ of the difference between normal duration and aggressive estimation (D). Then, the buffer size can be calculated using equation 1. Where $\mathrm{K}$ (scale parameter) is different based on Adaptive procedure with network density method or Adaptive approach with resource tightness.

$$
\begin{aligned}
& \text { Buffer size }=k * \sigma_{\text {path }} \\
& K=1+\text { network density } \\
& K=1+\text { maximum resouce tightness }
\end{aligned}
$$

After calculation, the buffer sizes of each method are listed below

1. Adaptive procedure with network density

Project buffer 1-2-3-8-9-13-14-16-19-21-22-23-24-25 $=(1.9)(13.72)=26$ days

Feeding buffer $6-10-17-18=(1.75)(5.63)=9$ days

Feeding buffer $7-17-18=(1.6)(2.59)=4$ days

Feeding buffer $5-11-12-15=(1.75)(6.24)=10$. ays

Feeding buffer $5-11-20=8$ days

2. Adaptive procedure with resource tightness

Project buffer 1-2-3-8-9-13-14-16-19-21-22-23-24-25 $=(1.9)(13.72)=20$ days

Feeding buffer $6-10-17-18=(1.75)(5.63)=9$ days

Feeding buffer 7-17-18 $=(1.6)(2.59)=4$ days

Feeding buffer $5-11-12-15=(1.75)(6.24)=8$ days

Feeding buffer $5-11-20=7$ days 
The buffer size obtained for each method is summarized in the table below. From the result got, For project buffer, the Adaptive procedure with network density method yields a larger buffer size than the adaptive approach with the resource tightness method. While for feeding buffer also show that APND resulted in a larger buffer size than APRT. The project buffer is placed at the end of the critical chain and resulted in additional 26 days. The 26 days is the time buffer to cope with any delays that might happen in the schedule. The yellow box indicated the buffer. The project buffer is placed at the end of the critical chain and resulted to additional 20 days. The 20 days is the time buffer to cope with any delays might happen in schedule.

Table 2: Buffer size result

\begin{tabular}{cccccc}
\hline Method & P.B. & F.B. 7-17-18 & F.B. 5-11-20 & FB 5-11-12-15 & FB 6-10-17-18 \\
\hline $\begin{array}{c}\text { Adaptive procedure } \\
\text { network density }\end{array}$ & 26 & 4 & 8 & 10 & 9 \\
$\begin{array}{c}\text { Adaptive procedure } \\
\text { resource tightness }\end{array}$ & 20 & 4 & 7 & 8 & 9 \\
\hline
\end{tabular}

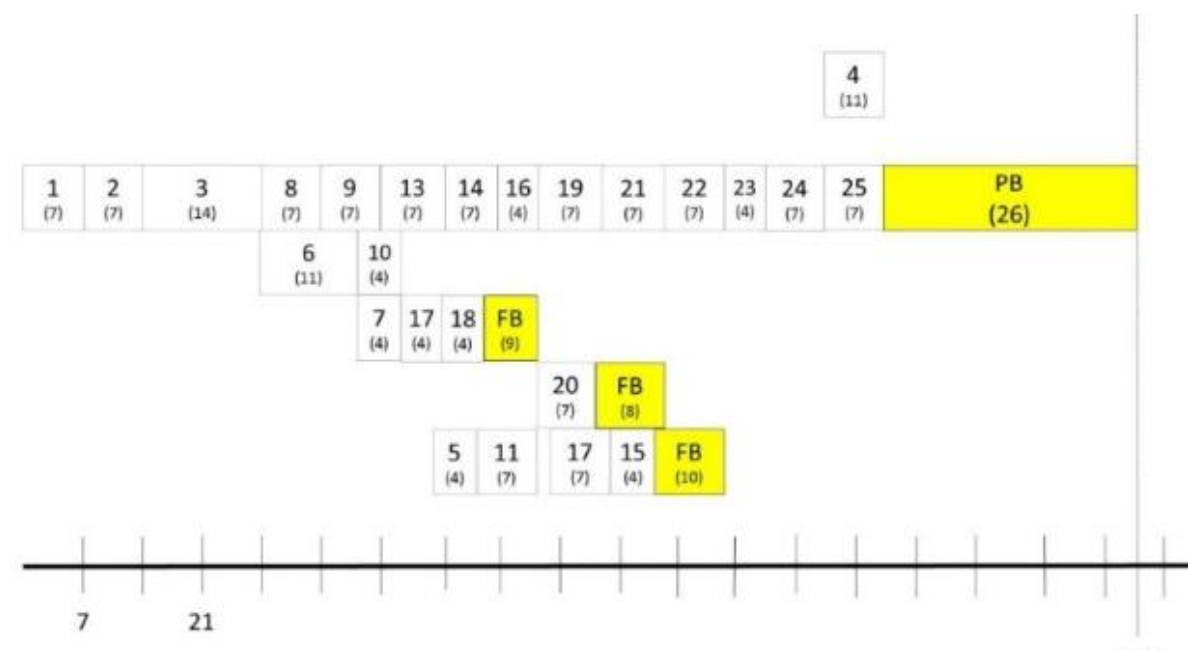

Figure 4: Buffer (APND

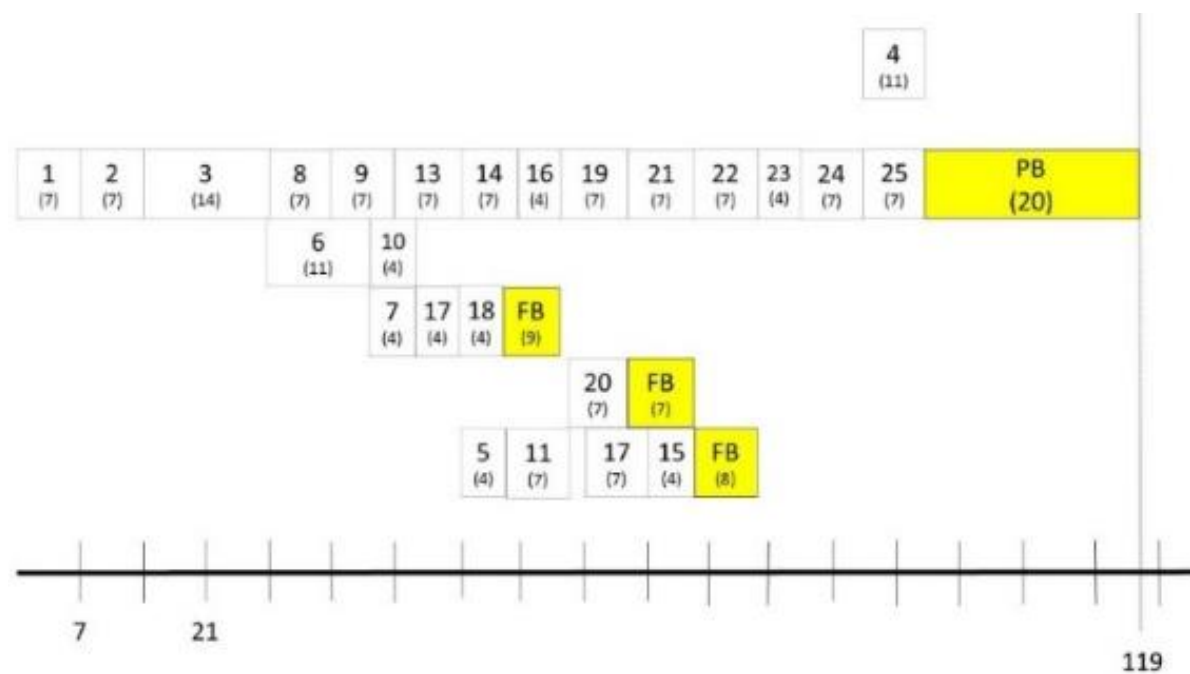

Figure 5: Buffer (APRT) 
Table 3: Result of simulation

\begin{tabular}{ccc}
\hline Remaining duration & Project completion (\%) & Buffer penetration \\
\hline 0 & $100 \%$ & $-380.77 \%$ \\
12 & $87.88 \%$ & $-334.62 \%$ \\
30 & $69.70 \%$ & $-265.38 \%$ \\
60 & $39.39 \%$ & $-150 \%$ \\
120 & $-21.21 \%$ & $80.77 \%$ \\
\hline
\end{tabular}

From the figure above, the differences between overall duration can be seen. The duration of the project using adaptive procedure with network density method is longer than adaptive procedure with resource tightness. A simulation that considers the possible scenario might happen in the project can evaluate the critical chain schedule. A project manager can determine the health of buffer or buffer consumption in the project schedule by using the Whatif simulation. The simulation to calculate buffer penetration is being done. The project manager reviewed the project progress on the fifth day of project execution. First, the project manager predicts that based on the planned project schedule. If the remaining duration to complete the project is 12 days left, the project is completed by $87.88 \%$ and penetrates the time buffer at -334.62 . The negative sign indicates that the buffer is not consumed yet. So the project is at no risk of being delayed and contrasted with estimating the remaining 120 days. In reviewing some uncertainty and problem might happen, the project manager estimate that the remaining days or possibility to complete the project is 120 days. So the project acts to be delayed and consume $80.77 \%$ of a time buffer. A negative sign of percentage of project completion shows that the project is delayed for 21 days. So the project finishes 21 days of 26 allocated project time buffer. Table 4 shows the result of the simulation generated from Microsoft excel.

After implementing and applying all necessary steps for the critical chain and buffer approach method, it is now possible to conclude which buffer location and sizing method should be proposed in the project. In selecting the buffer, the size method is depending on how risk-averse the project manager is. If the project manager is a risk-seeker who prefers a more extended deadline, an Adaptive procedure with a network density method is suggested to determine the buffer size as the APND yields a larger time buffer than Adaptive procedure with the resource tightness method. The buffer size generated from the adaptive procedure with resource tightness is preferable to high risk seeker. High risk seeker is the project manager who is planning to be competitive to finish the project earlier.

\section{CONCLUSIONS}

The actual life case study acquired from a local company is the project for production schedule being studied to apply the critical chain approach. Starting from review the provided schedule, the critical chain approach is implemented to the schedule and buffer management. There are six steps to be followed to achieve the aim of implementation. The results of each buffer sizing method are compared to select the suitable buffer size in the schedule. Due to lack of professional software to simulate and validate the efficiency of buffer size. Using Microsoft Project, one of the tools in project management, we can monitor the project. The Microsoft project feature such as Tracking Gantt, Report in progress, and resource overview assists the project manager. To simulate how buffer effect the schedule, the What-If concept simulation is designed using Microsoft excel. This simulation can help the project manager identify the project completion percentage and buffer penetration in the project schedule. A fever chart is also a tool used to check the time buffer's health in the schedule.

\section{ACKNOWLEDGEMENT}

The authors would like to acknowledge that the work have been conducted in the Department of Manufacturing and Materials Engineering, International Islamic University Malaysia. The authors are grateful to those who contributed directly and indirectly in producing this paper.

\section{REFERENCES}

1. Wickwire, J. M., \& Smith, R. F. (1974). The use of critical path method techniques in contract claims. Public Contract Law Journal, 1-45.

2. Aziz, R. F. (2014). RPERT: Repetitive-projects evaluation and review technique. Alexandria Engineering Journal, 53(1), 81-93.

3. Goldratt, E.H., "Critical Chain", Great Barrington, MA: North River Press. 1997

4. Zhao, Y., Cui, N., \& Tian, W. (2020). A two-stage approach for the critical chain project rescheduling. Annals of Operations Research, 285(1), 67-95.

5. Leach, L. P. (1999). Critical chain project management improves project performance. Project Management Journal, 30(2), 39-51. 
6. Iranmanesh, H., Mansourian, F., \& Kouchaki, S. (2016). Critical chain scheduling: a new approach for feeding buffer sizing. International journal of operational research, 25(1), 114-130.

7. Bhattacharjee S. K. (2011) Fundamentals Of PERT/CPM \& Project Management. Khanna Publishers

8. Shi, C., \& Gershwin, S. B. (2009). An efficient buffer design algorithm for production line profit maximization. International Journal of Production Economics, 122(2), 725-740.

9. Büchmann-Slorup, R. (2014). Applying critical chain buffer management theory in location-based management. Construction Management and Economics, 32(6), 506-519.

10. Tukel, O. I., Rom, W. O., \& Eksioglu, S. D. (2006). An investigation of buffer sizing techniques in critical chain scheduling. European Journal of Operational Research, 172(2), 401-416. 